\title{
EXPLORING INTRINSIC MOTIVATION AND KNOWLEDGE SHARING FROM THE PERSPECTIVE OF ISLAMIC TEACHING
}

\author{
Zuraina Dato' Mansor* \\ Universiti Putra Malaysia \\ Nor Siah Jaharuddin \\ Universiti Putra Malaysia
}

\begin{abstract}
Every individual has the option whether to share, or not to share their knowledge. Literature suggests that the motivation to share can be influenced by intrinsic or extrinsic factors. Intrinsic factors are normally initiated and are relative to the individual's interest, or intention. Extrinsic motivation is subject to the work environment, the support system, and the individual's organisation. Thus, the intention to share can be relative to the environment surrounding the individual. This paper aims to explain the intrinsic motivation factors for Knowledge Sharing (KS) among academics from a public higher education institution in Malaysia. In addition, it was proposed to study intention, and examine whether this was relevant to the concept based on Islamic teaching. Using the explorative study, the paper discussed the results based on a qualitative approach where eighteen academics were interviewed to collect data. Social Determination Theory (SDT) was used and, based on Islamic teaching, the paper study paid particular attention to the concept of brotherhood and 'ikhlas' (sincerity). The findings of the study were that academics acting as subject matter experts, understood their role to share knowledge and intrinsic motivation was a significant influence in their willingness to share. Further, based on Islamic teaching, it was found that the concept of 'ikhlas', or sincerity, and the concept of 'happy to help', or 'happy to see people happy', matched and coincided when they shared their knowledge.
\end{abstract}

Keywords: Academics; Intrinsic motivation; Knowledge sharing; Qualitative study

Received: 4 June 2018

Accepted: 5 February 2020

\section{INTRODUCTION}

Knowledge management literature emphasises the effects of intrinsic motivation in promoting knowledge sharing (KS) among the employees, believing it has a positive and lasting effect. Yet, how intrinsic motivation for knowledge sharing can be nurtured remains elusive and it is often left to random development (Pee \& Lee, 2015). KS creates opportunities for learning, application, and creation of new knowledge, which in turn reduces the costs of production, improves organisational performance, and enhances innovation capability (Wang, Yen, \& Tseng, 2015; Marouf, 2016). There is therefore a strong managerial interest in promoting KS (Pee \& Lee, 2015).

\footnotetext{
* Mansor, Z. D. \& Jaharuddin, N. S. (2020). Exploring Intrinsic Motivation and Knowledge Sharing from the Perspective of Islamic Teaching. International Journal of Business \& Society, 21(1), XX-XX.
} 
According to Wang et al. (2015), past studies on KS and motivational behaviour can be grouped into three categories; i. Organisational context: management support, rewards/incentives, organisational structure, interpersonal, team and cultural characteristics; ii. Individual factors: education, work experience and personality; and iii. Motivational factors: perceived benefits and costs, justice and trust. Acknowledging however the complexity of the subject induces researchers to explore some of the aspects in different organisational contexts, where different behaviours may occur, as well as different elements that may influence behaviour. Additionally, Welschen, Todorava and Mills (2012) and Pee and Lee (2015) pointed out that only a few of the studies undertaken examined the distinction between intrinsic and extrinsic motivations.

KS is voluntary behaviour and can be encouraged. Cabrera, Collins and Salgado (2006) considered that contributions to a KS repository are voluntary acts. Sharing knowledge is concerned with helping, sharing, cooperating and volunteering. In such cases, $\mathrm{KS}$ provides uncertain rewards and thus is not always motivated by explicit organisational rewards (Connelly \& Kelloway, 2003).

This paper is written to explore KS based on Self-Determination Theory (SDT) and Islamic teaching. According to Kazmi (2005), studies in management based on Islamic perspectives are an emerging field of enquiry in academia. Earlier, Mitroff and Denton (1999) also suggested that traditional assumptions between work and faith should be reconsidered. Other examples from Cash and Gray (2000) and Koys (2001), also suggested studies on integrating and accommodating religion in the workplace. The rationale for the study to be conducted in a public university in Malaysia was that Malaysia is known as one of the most progressive Islamic countries with significant economic growth (Kuppusamy \& Shanmugam, 2007), and as suggested by Bibi and Ali (2017) and Jolaee, Nor, Khani and Yusoff (2014), Islam encourage KS thus, as academicians, they must share their knowledge without too focus on the monetary rewards.

The motivation of whether to share or not may be addressed by theories of KS, and in this paper the concept was studied based on SDT. SDT distinguishes three motivational systems: intrinsic, extrinsic and amotivational. Intrinsic motivation originates from an individual's interest in the behaviour itself. Extrinsic motivation originates and is reinforced by certain rewards (monetary, status and deadlines, among others) and amotivation is a perceived lack of control over an individual's own behaviour (Zuckerman, Porac, Lathin, \& Deci, 1978). Further, SDT proposes that intrinsically motivated activities are those that provide psychological satisfaction of three innate needs: competence (self-efficacy), autonomy (internal locus of control) and relationship (Gagné, 2009; Ryan \& Deci, 2000). According to Islamic teaching, a tradition of more than 1400 years old, every individual is responsible for learning as well as sharing knowledge with other. In the Quran, Allah said: "And say: My Lord increases me in knowledge", in which it is understood that Allah has instructed His Prophet Muhammad, Peace Be Upon Him (PBUH), and all Muslims to ask Allah to increase them in knowledge. Similarly, another hadith from Sunan Al Tirmidhi, Prophet Muhammad (PBUH) states that seeking knowledge is obligatory upon every Muslim (male and female) ${ }^{2}$. This verse suggests that it is compulsory for people to learn and seek knowledge because knowledge will provide them a guide. Further, the Prophet

\footnotetext{
${ }^{1}$ Al-Quran, Taha 20:114

${ }^{2}$ Hadith Al-Tirmidhi, No 74
} 
Muhammad (PBUH) called upon all Muslims to obtain knowledge and then to disseminate what they have learned to others. This is supported by Hadith from Sahih Bukhari where the Prophet (PBUH) said, "Convey [what you learn from me] even if only one verse..." 3

According to Van den Hooff, Schouten and Simonovski (2012), when an individual makes his knowledge collective through sharing, the result is greater involvement and cooperation between the individual and community, team and organisation. Dyer and Nobeoka (2000) also indicated that KS would help communities work together and exchange knowledge, promote teamwork and organisational learning, and increase the potential for further individual and organisational performance.

This paper explored the intrinsic factors that motivate the intention of academics to participate in KS activities in a public university in Malaysia. The motivation to study this topic and the type of organisation was based on the following reasons: First, according to Sohail and Daud (2009), universities and colleges are centres of learning or knowledge hubs, and academics play a big role to this activity (Jolaee et al., 2014); therefore, it is the role of academics to act as models for KS activities. Additionally, according to Fullwood, Rowley and Delbridge (2012), universities, through their research activities should promote a culture in which knowledge creation becomes very important because the output of university researchers is disseminated through seminars, conferences, and publications. Further, academics may also share knowledge within teams and among their colleagues, as well as to external stakeholders, such as the local community, business organisations and private or government agencies. Based on this, it is expected that members of the university community know how to manage and utilise, as well as to maximise the utility of knowledge through sharing.

Second, according to previous literature there were various reasons KS at the workplace did not occur as much as it should have (Cabrera \& Cabrera, 2002) and that different levels and positions within an organisation lead to some people having more positive attitudes towards sharing compared to others (Constant, Kiesler, \& Sproull, 1994). Additionally, Ramachandran, Chong and Ismail (2009) suggest that there is a significant difference in the extent of knowledge dissemination practice between academics from public and private universities. For these reasons, an understanding of the antecedents for the motivation to share knowledge among university lecturers is of absolute importance (Chong, Yuen, \& Gan, 2014).

Third, although a strong body of KS research exists, there is still limited attention given to the intention and willingness of academics to become involved in KS, especially from the view of intrinsic motivation. According to Bock and Kim (2002), academic staff in universities share knowledge; however, their KS behaviour received little attention. Further, earlier research found dissimilar results on the effect of intrinsic motivation and KS. A study by Bibi and Ali (2017) suggests that a relationship between intrinsic motivation and KS behaviour cannot be proved. In other studies, however, such as Pérez, Cruz and Vaquero (2012), Cruz, Pérez and Cantero (2009), and Lin (2007), the results were the opposite. Hsu and Chang (2014) highlighted possible reason for the insignificant result, which included fear of losing knowledge power and reciprocity concerns.

\footnotetext{
${ }^{3}$ Hadith Ismail Bukhari, No 3461
} 


\section{LITERATURE REVIEW}

KS is an activity that involves an exchange of information or knowledge (both tacit and explicit), or that jointly creates new knowledge. When passed on, this knowledge can help others to perform related jobs or actions. Both the public and the private sectors should promote KS activities because the value of knowledge possessed by the individual within the company becomes greater when distributed to others, and it also contributes towards organisational performance and effectiveness (Kim \& Lee, 2006). This notion was supported by Noorazah and Juhana (2011), who suggested that employees should not hoard knowledge.

According to Islam, the concept of sharing knowledge is also seen as very important especially when people seek to earn the blessings of Allah (s.w.t.). According to a hadith by the Prophet Muhammad (s.a.w.): "Whoever is asked about knowledge and hides it, a bridle made of fire will be tied around his mouth on the Day of Resurrection" ".

Al-Husseini, Elbeltagi and Dosa (2015) defined knowledge as a multi-dimensional concept consisting of data, information, skills and experiences; combined, these assist individual and organisational in decision making. Organisational knowledge resides within the knowledge that workers create, archive, share and transfer during the performance of their jobs (Nonaka \& Konno, 1998). In addition, Gagne (2009) indicates that KS involves the process of mutually exchanging knowledge and jointly creating new knowledge, which together improves corporate synergy via the collaborative effort of individuals working toward a common goal.

Literature concerning a knowledge-based view of business suggests that knowledge could be a foundation for a firm's competitive advantage and value creation (Spender \& Grant, 1996), solving an organisations' problems and engaging in innovative activities (Al-Husseini, Elbeltagi, \& Dosa, 2015). Thus, performing activities relevant to knowledge management could impact the performance of an organisation (Susanty, Salwa, Chandradini, Evanisa, \& Iriani, 2016). Further, Susanty et al. (2016) suggests that the development of knowledge management will continue to grow and continue to be the subject of study.

\subsection{Motivation for $\mathrm{KS}$}

Past studies that explored motivational behaviour based on the SDT such as Ryan and Deci (2000), Bock and Kim (2002), Bock, Zmud, Kim and Lee (2005), Gagné (2009), Welschen et al. (2012) and Chen and Hsieh (2015), have proved it as useful in predicting KS and other voluntary behaviours (Gagné, 2009).

\subsubsection{Motivation Theories and KS}

Theories of motivation are a significant part of understanding why some people share and some do not. For example, Hendriks (1999) used Herzberg's two-factors theory to suggest that people share knowledge for two reasons; First, because they expect or hope for recognition and appreciation, promotional opportunities, or a sense of responsibility. Second, because of self-reciprocity, which is the hope the other party will share new knowledge in return.

\footnotetext{
${ }^{4}$ Narrated by Abu Hurairah, Hadith No. 8988
} 
Many previous studies also use the theory of planned behaviour (TPB) to support research in KS as it is related to individual intention. According to Ajzen (1991), TPB is defined as an intention that captures motivational factors and that can influence behaviour. Further, he added that the stronger a person's intention, the higher the potential that a person would act and behave based on what he or she believes.

This paper studies the intrinsic motivation based on self-determination theory (SDT). According to this theory, different types of motivation derive from different reasons or goals (Deci \& Ryan, 1985). They define intrinsic motivation as doing something because it is inherently interesting or enjoyable, and internal factors (i.e., autonomous motivation) include self-interests, enjoyment, and selfless care for other parties. The need for relationship, support this paper to explore the concept of 'ikhlas' according to the Islamic teaching. Ikhlas (sincerity) is important for the acceptance of the deeds because the Prophet (PBUH) said that niyyah (intention) for every person's deeds will be rewarded according to what he has intended.

Past literature suggests that intrinsic motivation was intensively studied in psychology (McAuley, Duncan, \& Tammen, 1989). Recent empirical studies consider intrinsic motivation to highly impact on KS (Yan \& Davison, 2013; Pee \& Lee, 2015), and it is assumed to be an important key factor in explaining KS (Welschen et al., 2012; Wasko \& Faraj, 2000).

\subsubsection{Motivational Factors and KS}

Since the 1990s, practitioners have been seeking the most effective ways for motivating and encouraging experts or knowledge workers to be involved in KS activities. Literature suggests many factors that could influence the process such as; organisational structure (centralised and decentralised), technical infrastructure, trust, motivation, sense of community (Sharrat \& Usoro, 2003), as well as opportunistic behaviour and politicking (Willem, 2003).

According to Islam, every Muslim is a brother to another Muslim; therefore, they should perform good deeds to each other, which includes sharing knowledge. The Prophet (PBUH) said, "When $a$ man dies, all his deeds come to an end except for three-an on-going charity, beneficial knowledge [that he disseminates to others] and a righteous son who will pray for him". 5

Past literature also suggest that the quality of experiences and performances could be different when one is behaving for intrinsic versus extrinsic reasons (Deci \& Ryan, 1985). Lin (2007), who studied motivation based on extrinsic and intrinsic factors, suggests that an external source of motivation are goal-driven rewards (Deci \& Ryan 2000), while intrinsic motivation is based on individual internal interest and satisfaction (Deci, 1975). This notion was supported by Susantri and Wood (2011) who suggested that employees participated and became involved when they assumed there were rewards for their behaviour (extrinsic value) such as monetary rewards, gift certificates, or recognition. Additionally, Reinholt, Pedersen and Foss (2011) found that employees were most involved in KS when network centrality, motivation, and capabilities were supportive. These findings support the argument that employees need motivation to be fully involved in the KS activities. The finding also was in line with a study from Javadi, Zadeh, Zandi and Yavarian

\footnotetext{
${ }^{5}$ Hadith Muslim, No 1631
} 
(2012) who found there was a positive and significant relationship between work motivation and KS.

This study is focused on intrinsic motivation. This is based on the notion that intrinsic motivation is not necessarily fully determined by the social context (Ryan \& Deci, 2000), but rather that employees can be exposed to a similar social climate which influences their attitude and behaviour. According to Nili, Isfahani and Tanhaie (2013), employees' attitude could directly or indirectly affect the motivation towards KS. Their notion was similar to Grant and Rothbard (2013) who suggest that employees are heterogeneous with respect to their work-related attitudes, motives, behaviours and values.

\subsection{Academic and KS behaviour}

KS is crucial for knowledge-based organisations like universities (Cheng, Ho, \& Lau, 2009). Academics must engage in KS especially with respect to research and teaching (Fullwood, Rowley, \& Delbridge, 2013). In addition, universities must resolve knowledge gaps (Martin \& Marion, 2005) and develop a healthy environment for knowledge transfer.

Goh and Sandhu (2013) pointed out that it is a norm and culture in an academic institution that senior academic staff must share knowledge and expertise with junior academics in order to improve the processes of learning and teaching. Sohail and Daud (2009) stated that academics' willingness to exchange and disseminate knowledge is important to intensify and boost academic and research excellence.

According to SDT, intrinsically motivated activities are those that provide psychological satisfaction of three innate needs: competence (self-efficacy), autonomy (internal locus of control) and relationship (Gagné, 2009; Ryan \& Deci, 2000). Based on these needs, data was collected based on intrinsic factors as described below.

a. SDT (Self-Efficacy)

Self-efficacy could influence peoples' decisions and motivate individuals' behaviour. SDT indicated that as long as an activity increases the feelings of competence (self-efficacy), the individual would feel motivated to engage in the activity (Ryan \& Deci, 2000), and individuals with high self-efficacy, are more willing to share their knowledge (Bock \& Kim, 2002).

\section{b. SDT (Autonomy)}

Autonomy concerns whether the job gives the employee the opportunity to decide when and how to carry out specific tasks. Deci and Ryan (1985) suggested autonomous motivation as doing something because it is inherently interesting or enjoyable, and the factors include self-interests, enjoyment, and selfless care for other parties.

\section{c. SDT (Relationship)}

SDT attested that there is a relation between relationship needs and intrinsic motivation (Deci \& Ryan, 2000). If individuals perceive that KS will improve their relationship with other employees, it will positively influence attitudes regarding KS (Bock \& Kim, 2002). People are more willing to 
share knowledge if it is appreciated and they perceive that their knowledge will be used (Hall, 2001).

Additionally, based on past literature reviews, this paper also looked on other intrinsic motivation factors that could influence KS behaviour. This was done to support this qualitative study, where it is important to support building KS themes. The paper has chosen the following elements/factors.

\section{d. Enjoyment in Helping Others}

Intrinsic and intangible incentives encourage individuals to engage in a social relationship to perform a specific task for its own sake (Mallasi, 2012). Past literature suggests that people are intrinsically motivated to participate in KS because in doing so it would help others, and it would make them feel pleasure (Wasko \& Faraj, 2005). This is also known as enjoyment in helping others and is strongly associated with attitude (Chennamaneni, Teng, \& Raja, 2012) and willingness (Lin, 2007). In public organisations, it is acknowledged that employees sometimes share knowledge not because of the extrinsic rewards but because of their positive attitude (Bock \& Kim, 2002).

\section{e. Trust}

According to Choi, Kang and Lee (2008) trust is very important and in fact is more important than technical support in facilitating KS. This is because trust removes deception, cheating and the tendency to blame others (Nonaka, 1990). Additionally, Wang, Tseng and Yen (2012) pointed out that when relationships were built based on trust, people were willing to share, listen and absorb more. Further, Ismail and Yusoff (2010) and Javadi et al. (2012) added that by having a trusted relationship, a better quality and process of KS would take place. Based on this, it is predicted than when there is trust between the people, their intention towards the action will be more sincere. Prior studies have also shown there is a correlation between trust and self-efficacy (e.g., Pavlou \& Fygenson, 2006; Cheung \& Chan, 2000).

Trust is perceived as honesty, sincerity and a natural and essential component of relationships (Gabarro, 1978; Rempel, Holmes, \& Zanna 1985). With reference to Islamic teaching, this motivation can be related to the concept of ikhlas or sincerity.

\section{f. 'Ikhlas' or Sincerity}

Muslims are taught that Ikhlas is to do things for the sake of desiring the pleasure of Allah. 'Sincere', according to Collins English Dictionary, is defined as genuine, unmixed, and not hypocritical. Imam al-Ghazali said that if you want to know whether something you did was purely for the sake of Allah or not, you should test your reaction when someone acts ungratefully. For example, when the person to whom you did good, did not appreciate your work, you will feel angry, or when you did something you are expecting, at the very least, recognition and respect from the person as a result, this is not 'ikhlas'. Al-Bukhari and Muslim narrated that Umar (RA) said, "I heard the Messenger of Allah say: "Verily, the reward of deeds depends upon the Niyyah (intentions) and every person will get the reward according to what he has intended." 6 , and 'ikhlas' lied in this, where you should not expect rewards from people but Allah.

\footnotetext{
${ }^{6}$ Hadith Al-Bukhari and Muslim
} 


\section{g. Top Management Support}

The failure or success of organisational activities in general is related to the leaders' and superiors' support (Lee, Shiue, \& Chen, 2016). Other researchers such as Connelly and Kelloway (2003), King and Marks Jr (2008) also pointed out that there was a positive correlation between management support and KS culture.

\section{METHODOLOGY}

According to Lin (2007) studies on KS that used exploratory and qualitative approaches were still limited, especially within the educational sectors. This study employed a qualitative method as it explored the motivational factors of academics to be involved in KS activities. Past literature suggests that qualitative methods play a vital role in applied research because they provide a deeper examination and realisation of the human experience (Watkins, 2012; Watkins \& Gioia, 2015). Further, this method helps researchers to acquire in-depth information surrounding a phenomenon of interest (Watkins \& Gioia, 2015). Additionally, according to McNamara (1999), interviews are particularly useful for getting to the story behind a participant's experiences, this is because, the interviewer can pursue in-depth information around the topic and there is opportunity for followup (McNamara, 1999).

The study used respondents selected from five faculties in a public university. They represented a variety of academic levels, including professors, associate professors, senior lecturers, and a young tutor. They were contacted either personally by the researcher or through the referral of colleagues. Academics of different professional status were used to ensure that the respondents were selected strategically. A range from professor to young tutor was included because it was expected that the varied lengths of their working lives would introduce varied experiences and different levels of knowledge. The respondents in this research were three professors (P), five associate professors (AP), nine senior lecturers (SL) and 1 young tutor/lecturer (T). Further, to make the data wider and more rigorous, these eighteen academics were selected from various disciplines and backgrounds including economics, finance, management, ecology, modern languages, education, agriculture, science, and information technology.

The data used for the discussion in this paper was collected using an individual in-depth interviewing process based on extensive qualitative research. Interviews are a useful way of acquiring large amounts of data. This research involved a number of respondents to allow for a wide variety of information, especially on a potentially large number of topics, and triangulation of the data. Immediate follow-up questions were also allowed as the research used semi structured questions during the interviews. Acknowledging that the interviews were conducted with academics, the questions were asked in English, however respondents were free to answer in both or either of English and Malay when responding.

The interviews were conducted in person and were audio-recorded. Each of the interviews took about one hour and thirty minutes to two hours. The interview was guided by the themes and contents analysis of the research literature reviews, and the respondents were asked approximately twelve questions. To ensure that the process of obtaining the data was well-organised and structured, a consistent set of questions for all respondents was monitored. The interviews started 
by asking respondents questions concerning their teaching and learning backgrounds, to create a sense of confidence as they described their expertise. The participants were then asked questions relevant to their intention and willingness as well as their motivation to share knowledge. Interviews were subsequently fully transcribed and translated into the English language, to allow for an excellent understanding between the respondents and the researcher/interviewer. It was found that overall every academic was enthusiastic in describing his or her professional journey and telling stories about teaching and learning. Each time an interview was finished, the data was transcribed for the purpose of coding and analysis, then later was used to discuss the findings.

The translations and interpretations that were undertaken after the analysis were checked by two academics. For interpreting the data to be used for research findings, the researcher ensured that data was collected using a method that would support narrative analysis. According to Labov and Waletzky (1997), narrative analysis was one method of recapitulating past experience by matching a verbal sequence of clauses to the sequence of events that actually occurred. In this situation, the authors gave priority to assess in terms of how those narratives' answers reflected the motivation of each respondent. Thus, the richness of the story of their experiences was very important. Once the researcher summarised the information points, the outcomes were shown to two academics for validation. Polit and Beck (2011) states that in order to increase the rigorousness of qualitative data, the researcher needs to send the transcripts to the respondents and encourage them to read, amend and verify the accuracy of the interview dialogues.

\section{RESULTS}

Research on SDT suggests that intrinsically motivated efforts enable individuals to fulfil their basic psychological needs for autonomy, competence and relatedness, which are essential nutriments for optimal human development and integrity (Gagné, 2009). Individuals feel autonomously motivated when they perceive self-determination based on self-interests, curiosity, care, or abiding values. The autonomous factors that motivate individuals to involve in KS include selfinterests/commitment, enjoyment and satisfaction to help people, or care for other parties. Finally, with regards to relatedness, if the activity supports an individual's need for relationship, it will lead to intrinsically motivated behaviour.

This paper examined how academics see the role of intrinsic motivation in supporting their willingness to share their knowledge with others. Incorporation of different seniority levels of academics helped to reduce the bias of limiting the study focus to one level only. The findings derived from the collected data are discussed below.

\subsection{The Role of Academics and Motivation in Sharing Knowledge}

Past research has acknowledged the role of academics in teaching and learning. For example, Sohail and Daud (2009) stated that being in the university it is the role of academics to act as models for KS activities. This notion is supported by Fullwood et al. (2012) who suggests that universities, through their research activities should promote a culture of knowledge creation. Based on both literatures, the researcher started the conversation by asking the respondents about their views of KS as academics. All the respondents acknowledged their responsibility to share 
knowledge, especially with students, with peers and colleagues, and with anyone who asks for their expert knowledge.

Further, the respondents said that as academics, being involved in KS activities formally or informally (by request or not) was really an expression of the personality of an academic. This is because, once an academic is in the job, the role and responsibility mainly involved KS activities. The internal spirit would always push academics to share knowledge, especially with colleagues who belong in one team, and who share the same interests. By sharing, they gained experience and increased self-efficacy. As SL15 said,

"whenever I shared my knowledge, I gained new experience". (SL15)

Based on the responses, the researcher would also suggest that academics are often intrinsically motivated to be involved in KS. For example, SL11 said that the willingness to share was motivated by her happiness in doing it, and she was especially willing to share within the area of her interest whether she was rewarded or not.

"I share my knowledge because I myself am willing to do it and happy to do it. I like to see people solve their problems using the knowledge that I shared with them." (SL11)

\subsection{Motivation for $\mathrm{KS}$}

The motivation to share knowledge increases as individuals participate in KS, including academics (Sohail \& Daud, 2009). The motives to do so however (and the situations that lead them to share or not) can be influenced by other factors which act either as a barrier or enabler for KS (Sondergaard, Kerr, \& Clegg, 2007). When the person expects to receive benefits, it will promote him/her to share, and when there is a fear of losing valuable resources, it will restrict him/her to share the experiences. Wasko and Faraj (2005) and Chennamaneni, Teng and Raja (2012) suggested that an intrinsically motivated person found enjoyment in helping others and this is related to their attitude. In general, the following discussion of results from this study is similar to the findings from earlier research.

After the respondents were asked about their understanding of their role as academics, the researcher then asked what could be their reasons to share their knowledge, i.e. whether it was something intrinsic or extrinsic. Based on the responses given, the results showed that all of the respondents reported a willingness to share knowledge for reasons that were related to intrinsic motivation. This was because (they stated) as academics they knew it was their responsibility to share in order to help solve problems or that KS would make them feel better or happy knowing that someone else was able to utilise the knowledge they shared. As they became more confident with the knowledge that they possessed, their willingness to share increased.

Few respondents mentioned that, knowing their responsibility and duty to share, there was any pressure or force needed to make them share. In addition, some lecturers further assured that as time passed and they became confident with their knowledge and expertise, their willingness to share will increase and they became very confident to share knowledge. This would make them happy to share knowledge whenever there is opportunity given. Because of this reason also however, some academics said that they started to struggle between sharing to gain recognition 
(e.g., need for others to think positively about him/her), or other tangible rewards (such as career promotion or getting monetary rewards), or sharing because wanted to help other people. This took place as people acknowledge and recognise their expertise. Further, the key performance index (KPI) for academics in a public university highly recognises the KS involvement. Those who have high score will be given a higher priority for tangible rewards such as promotion, and so on.

"Both intrinsic and extrinsic motivations are important. Extrinsic value is important because it is related to our KM Portal or KPI and networking." (S12)

"I feel responsible for helping my students to develop themselves for future careers. However, salary and other rewards such as job promotion, and social acceptance do matter and support my contributions in sharing the knowledge." (SL11)

"I become passionate to share my knowledge knowing people want to know something from me... they use me as a reference." (P2)

"I used to be not so open when sharing, but now I am very confident, I also belong to a professional group. Now I enjoy doing it. In fact, I am willing to do it anytime.” (P1)

"We are referred, that shows people recognised us, therefore, why should we hoard our knowledge. Whether we are getting rewards or not, it is another issue, what is more important is people seek for our expertise, our knowledge, and our advice and people come to you because they know you possess the right knowledge to help them solve their issues" (P3)

"I enjoy myself every minute doing it, spending my time as lecturer, and even as a professor". (P4)

a. Enjoyment, Helping Others and Self-Satisfaction

Respondents suggested how passionate academics can be about sharing their knowledge: For example, as respondent AP6 said,

"If I share I get satisfaction. For me, what is the point of having knowledge without sharing?" (AP6)

"There is nothing extrinsic that makes me want to share knowledge because I feel knowledge is everybody's. So we must share knowledge because if we keep the knowledge, it does not get very far. I also like to see people's success." (AP8)

"I love sharing my knowledge maybe because I was brought up in a family of teachers, so naturally sharing knowledge was part of my passion”. (AP9)

b. Strengthening the Relationship

Based on the respondents, it can be suggested that, the determination to share knowledge was strongly connected to intrinsic motivation, be it due to 'happy- to-help' people, build / strengthen relationships, sincere desire, feeling competent, or happy to see other people solve problems. This leads to the conclusion that people share when they have positive emotions (liking, empathy) and, 
as suggested in SDT, the results support the notion that KS is closely connected to the fulfilment of the need for relatedness, especially because it helps involved people to build, develop and maintain social ties with colleagues. The result was also similar to the study by Reinholt et al. (2011) who suggests that some employees tend to be naturally engaged in KS with others. Whether the willingness to share however is related to the personality or attitude of the person can be tested in the future research.

This research further explored whether the willingness to share was subject to any situation or conditions. Based on the responses, the level of willingness to share can be related to certain conditions. For example, most academics suggested they shared more when people enquired or asked, in order to ensure that the knowledge was something that others wanted to hear, or something in which they have interest.

"I am willing to share with those who want it because I know they will appreciate it when listening." (SL14)

\section{c. Trust and 'Ikhlas'}

Trust is essential for social interaction and the mutual exchange process, and plays a vital role in the KS process (Pai, 2006). Past researchers believe that people willingly exchange knowledge with each other when trust exists among them (Bakker, Leenders, Gabbay, Kratzer, \& Van Engelen, 2006). Academics normally have a good relationship among themselves. The findings suggest that academics pointed to the important of relationships among themselves as influencing their willingness to share the knowledge. This is especially true if they belong to the same team or share similar areas of interest, or if they are close friends, they would involve in KS activities voluntarily and sincerely, as they believed the value of friendship would overcome other tangible rewards. Some of the respondents' answers are given below.

"I would share more with people who are closer to me because I know he or she is also looking forward to those new updates of such knowledge, and also if they asked anything, they are the one to whom I can't say 'no' (SL11)"

"Between senior and junior there is always a gap but between peers it is different. For example, me and my colleague, we are quite open, we share similar interests, and thus we are happier to share because we can always work together for a paper and publication. (AP5)"

"My willingness to share will increase if they are my close friends, in the sense that they do not have to ask. (AP8)"

There were also academics however that believed sharing knowledge did not require one to be close to one another, but rather because religion teaches them to do so, then they will do it. This attitude we believed was related to the concept of 'ikhlas' or sincerity according to Islamic teaching.

"I am willing to share my knowledge with everybody whether I get reward or not. It is because I believe sharing our knowledge is part of our responsibility, Islam teaches us that, but even you are not Islam, if you have good personality, it will drive you to always help people" (SL17) 
In addition, as the academics have achieved higher recognition, the values for tangible rewards were concluded to not have superseded the intrinsic motivation. This is based on the responses given by the professors who were involved in this study. They were already very confident with their knowledge, and most of the time they were recognised as authoritative sources.

\subsection{Situations leading to $K S$}

a. Sharing When it Gives Pleasure and Represents A Good Attitude

Past literature states that intrinsic motivation for KS is closely related to a feeling of enjoyment in helping others and represents a good attitude (Chennamaneni, Teng, \& Raja, 2012). This was observed in the findings of this study, where the respondents suggested that when people come to seek their expertise, they felt some responsibility to put the effort in to help them. Some of the respondents also stated that the interest in doing good deeds via KS was in the knowledge they would be rewarded by the God (Allah).

"I will share if I know something whether through my expertise or other knowledge, because by doing so, I help people do the right thing or I can correct a mistake (e.g. something regarding a religious issue). I will do it to gain pleasure from Allah. (SL10)”

"I am always positive. I know that if I shared the knowledge, it will benefit people. I will do it whenever and wherever possible. My intention is to get rewards for doing good deeds. (P3)"

b. Sharing When There Is Support from Top Management

The respondents also mentioned the need for support from management, leaders, and teams in increasing their motivation to share knowledge. This is because they said support from these entities is very important in promoting the engagement and passion for sharing that is characteristic of a widespread culture of KS.

"I would love to get support from management that provides a good infrastructure and environment. The support is important. (AP9)",

"Willingness to share needs trust, leadership support, and a cohesive team. (SL16)"

"We can start with passion to share with people, but the support from leaders and management do count. For example, please don't be biased. Sometimes, leaders or management overemphasised or discriminate us, we are only recognised because of achievement or meeting KPI, because of that indirectly we become attached to extrinsic rewards" (SL17)

In summary, it can be said that situations that influenced the decision to share knowledge among academics involved a request, the relationship between the contributor and the receiver, the confidence level of the knowledge contributor towards his or her knowledge, and the attitude towards KS. 


\section{DISCUSSION AND CONCLUSION}

This paper focused on exploring the role of intrinsic motivation in supporting KS among the academics. The study used SDT. The overall findings supported the earlier research on KS based on SDT. According to Gagne (2009), research on SDT suggests that intrinsically motivated efforts enabled individuals to fulfil their basic psychological needs for autonomy, competence and relatedness. Individuals felt autonomously motivated when they perceive self-determination in selecting their objectives freely based on self-interests, curiosity, care, or abiding values. The internal/autonomous motivating factors included self-interests, enjoyment, and selfless care for other parties. SDT also attested that there is a relation between relationship needs and intrinsic motivation (Deci \& Ryan, 2000).

The paper also attempted to explore KS based on Islamic teaching. One of the concepts is brotherhood based on the relationship. The concept of brotherhood teaches that every Muslim is responsible to do good deeds to another Muslim and this includes sharing their knowledge. The benefit would be rewarded especially in the afterlife. The activity or actions would be considered 'ikhlas' or sincere, if the person performed the deeds without expecting a return from the other party or anybody. The paper found that the intrinsic factors that motivate academics to share their knowledge include; 'happy to help' other people, to build or strengthen relationships, sincere desire and happy to see other people solving problems, which are all relevant to the concept of brotherhood. These results are in line with other scholars who suggested that intrinsic motivation such as 'happy to help' others would make them feel pleasure (Wasko \& Faraj, 2005), improve their relationships (Bock \& Kim, 2002) and would positively influence attitudes regarding KS.

Another contribution from the study was sincerity of the concept of ' $i k h l a s$ ' as per Islamic teaching. This motivation on the concept of 'ikhlas' is also relevant to trust and good attitude. When you have trust with others, you will behave accordingly. Yang (2008) states that employees' attitudes and competencies may impede KS. Earlier, Hislop (2003) points out that employees' attitude can be very influencing factor in KS. In a research on KS behaviour and trust, Wang, Yeng and Tseng (2015) suggests that workers' trust in other organisational members encourages them to share knowledge and thus interpersonal trust is recognised as essential. Based on this, it is anticipated that the closer the relationship between members, the more people trust them, and the more they would share the knowledge sincerely without expecting any tangible rewards.

In conclusion, the findings supported the proposition that intrinsic motivational factors and Islamic teaching about $\mathrm{KS}$ are consistent.

\section{MANAGERIAL IMPLICATION AND RECOMMENDATION}

It is believed that policy makers and those in management should emphasise the growth of knowledge, and that individuals should be encouraged to promote KS without depending on extrinsic rewards. Everyone should be encouraged to participate actively and more frequently in KS activities to help Malaysian higher education institutions achieve its objective of becoming a centre of excellence. Thus, based on the results, we recommend the university to cultivate a culture of brotherhood among its academics. High levels of teamwork or projects focused on teamwork should be given attention. It is believed that close relationships motivate and facilitate the sharing 
of knowledge. The upper management should activate a forum of feedback among the academics and management teams. This would help faculty, students, and researchers in getting opinions and feedback from the referent groups of the academics (e.g. peers, department head, dean, vice chancellor); this is similar to the operation of WhatsApp, where instant questions and answers spread very fast and easy among people of interest. The hope is that by doing this, the university could exert pressure on academics to engage in KS, while the academics could enhance their individual sense of self-worth. The university administrators, such as faculty deans and the heads of departments, should also encourage an open and conducive environment that welcomes new ideas, is open to criticism, and constantly strives for unity among the staff. This would encourage $\mathrm{KS}$ regardless of status or the relationship one person may have with another.

\section{ACKNOWLEDGEMENT}

This study was funded through GUPM under University Putra Malaysia.

\section{REFERENCES}

Al-Husseini, S. J., Elbeltagi, I. M., \& Dosa, T. A. (2015). Knowledge sharing processes as critical enablers for process innovation. International Journal of Culture and History, 1(1), 3338.

Ajzen, I. (1991). The theory of planned behavior. Organizational Behavior and Human Decision Processes, 50(2), 179-211.

Bakker, M., Leenders, R. T. A., Gabbay, S. M., Kratzer, J., \& Van Engelen, J. M. (2006). Is trust really social capital? Knowledge sharing in product development projects. The Learning Organization, 13(6), 594-605.

Bibi, S., \& Ali, A. (2017). Knowledge sharing behavior of academics in higher education. Journal of Applied Research in Higher Education, 9(4), 550-564.

Bock, G. W., \& Kim, Y. G. (2002). Breaking the myths of rewards: An exploratory study of attitudes about knowledge sharing. Information Resources Management Journal, 15(2), 14-21.

Bock, G. W., Zmud, R. W., Kim, Y. G., \& Lee, J. N. (2005). Behavioral intention formation in knowledge sharing: Examining the roles of extrinsic motivators, social-psychological forces, and organizational climate. MIS Quarterly, 87-111.

Cabrera, A., \& Cabrera, E.G. (2002). Knowledge-sharing dilemmas. Organization Studies, 23(5), 687-710.

Cash, K. C., \& Gray, G. R. (2000). A framework for accommodating religion and spirituality in the workplace. Academy of Management Executive, 14(3), 124-134.

Cabrera, A., Collins, W. C., \& Salgado, J. F. (2006). Determinants of individual engagement in knowledge sharing. The International Journal of Human Resource Management, 17(2), 245-264.

Chen, C. A., \& Hsieh, C. W. (2015). Knowledge sharing motivation in the public sector: The role of public service motivation. International Review of Administrative Sciences, 81(4), 812-832. 
Cheng, M. Y., Ho, J. S. Y., \& Lau, P. M. (2009). Knowledge sharing in academic institutions: A study of multimedia university Malaysia. Electronic Journal of Knowledge Management, 7(3).

Cheung, C. K., \& Chan, C. M. (2000). Social-cognitive factors of donating money to charity, with special attention to an international relief organization. Evaluation and Program Planning, 23(2), 241-253.

Chennamaneni, A., Teng, J. T. C., \& Raja, M. K. (2012). A unified model of knowledge sharing behaviours: Theoretical development and empirical test. Behaviour \& Information Technology, 31(11), 1097-1115.

Choi, S. Y., Kang, Y. S., \& Lee, H. (2008). The effects of socio-technical enablers on knowledge sharing: An exploratory examination. Journal of Information Science, 34(5), 742-754.

Chong, C. W., Yuen, Y. Y., \& Gan, G. C. (2014). Knowledge sharing of academic staff: A comparison between private and public universities in Malaysia. Library Review, 63(3), 203-223.

Connelly, C. E., \& Kelloway, K. (2003). Journal predictors of employees' perceptions of knowledge sharing cultures. Leadership \& Organization Development Journal, 24(5), 294-301.

Constant, D., Kiesler, S., \& Sproull, L. (1994). What's mine is ours, or is it? A study of attitudes about information sharing. Information Systems Research, 5(4), 400-421.

Cruz, N. M., Pérez, V. M., \& Cantero, C. T. (2009). The influence of employee motivation on knowledge transfer. Journal of Knowledge Management, 13(6), 478-490.

Deci, E. L. (1975). Intrinsic Motivations. New York: Plenum.

Deci, E. L., \& Ryan, R. M. (1985). Intrinsic Motivation and Self-determination in Human Behavior. New York: Plenum.

Deci, E. L., \& Ryan, R. M. (2000). The 'what' and 'why' of goal pursuits: Human needs and the self-determination of behavior. Psychological Inquiry, 11(4), 227-268.

Dyer, J. H., \& Nobeoka, K. (2000). Creating and managing a high performance knowledge sharing network: The Toyota case. Strategic Management Journal, 21(3), 345-367.

Fullwood, R., Rowley, J., \& Delbridge, R. (2012). Knowledge sharing amongst academics in UK universities. Journal of Knowledge Management, 17(1), 123-136.

Gabarro, J. J. (1978). The development of trust, influence and expectations. Interpersonal Behavior: Communication and Understanding in Relationships, 290-303.

Gagne, M. (2009). A model of knowledge sharing motivation. Human Resource Management, 48(4), 571-589.

Goh, S. K., \& Sandhu, M. S. (2013). Knowledge sharing among Malaysian academics: Influence of affective commitment and trust. Electronic Journal of Knowledge Management, 11(1).

Grant, A. M., \& Rothbard, N. P. (2013). When in doubt, seize the day? Security values, prosocial values, and proactivity under ambiguity. Journal of Applied Psychology, 98(5), 810-819.

Hall, H. (2001). Input-friendliness: Motivating knowledge sharing across intranets. Journal of Information Science, 27(3), 139-146.

Hislop, D. (2003). Linking human resource management and knowledge management via commitment: A review and research agenda. Employee Relations, 25(2), 182-202.

Hendriks, P. (1999). Why share knowledge? The influence of ICT on the motivation for knowledge sharing. Knowledge and Process Management, 6(2), 91-100.

Hsu, M. H., \& Chang, C. M. (2014). Examining interpersonal trust as a facilitator and uncertainty as an inhibitor of intra-organisational knowledge sharing. Information Systems Journal, 24(2), 119-142. 
Ismail, M. B., \& Yusof, Z. M. (2010). The impact of individual factors on knowledge sharing quality. Journal of Organizational Knowledge Management, 10, 1-12.

Javadi, M. H. M., Zadeh, M. D., Zandi, M., \& Yavarian, Z. (2012). Effect of motivation and trust on knowledge sharing and effect of knowledge sharing on employee's performance. International Journal of Human Resource Studies, 2(1), 210-221.

Jolaee, A., Nor, K.M., Khani, N. and Yusoff, R.M. (2014). Factors affecting knowledge sharing intention among academic staff. International Journal of Educational Management, 28(4), 413-431.

Kazmi, A. (2005). Probable differences among the paradigms governing conventional and Islamic approaches to management. International Journal of Management Concepts and Philosophy, 1(4), 263-289

Kim, S., \& Lee, H. (2006). The impact of organizational context and information technology on employee knowledge-sharing capabilities. Social Science Journal, 66(3), 370-385.

King, W. R., \& Marks Jr, P. V. (2008). Motivating knowledge sharing through a knowledge management system. Omega, 36(1), 131-146.

Koys, D. J. (2001). Integrating religious principles and human resource management activities. Teaching Business Ethics, 5(2), 121-139.

Kuppusamy, M., \& Shanmugam, B. (2007). Islamic countries economic growth and ICT development: The Malaysian case. Journal of Economic Cooperation, 28(1), 99114.

Labov, W., \& Waletzky, J. (1997). Narrative analysis: Oral versions of personal experience. Journal of Narrative and Life History, 7(1/4), 3-38.

Lee, J. C., Shiue, Y. C., \& Chen, C. Y. (2016). Examining the impacts of organizational culture and top management support of knowledge sharing on the success of software process improvement. Computers in Human Behavior, 54(2), 462-474.

Lin, H. F. (2007). Effect of extrinsic and intrinsic motivation on employee knowledge sharing intentions. Journal of Information Science, 33(2), 135-149.

Marouf, L. (2016). The role of knowledge sharing culture in business performance. VINE Journal of Information and Knowledge Management Systems, 46(2), 54-174.

Mallasi, H. I. (2012). Knowledge Sharing Behaviour among Postgraduate Students: A NonMonetary Approach (Unpublished PhD Dissertation, University of Malaya).

Martin, J. S., \& Marion, R. (2005). Higher education leadership roles in knowledge processing. The Learning Organization, 12(2), 140-151.

McAuley, E., Duncan, T., \& Tammen, V. V. (1989). Psychometric properties of the Intrinsic Motivation Inventory in a competitive sport setting: A confirmatory factor analysis. Research Quarterly for Exercise and Sport, 60(1), 48-58.

McNamara, C. (1999). General guidelines for conducting interviews, Minnesota. Missouri Institute of Science.

Mitroff, I. I., \& Denton, E. A. (1999). A study of spirituality in the workplace. Sloan Management Review, 40(4), 83-92.

Nili, M., Isfahani, A. N., \& Tanhaie, M. H. (2013). Knowledge sharing and its impact on employees' motivation. International Journal of Academic Research in Progressive Education and Development, 2(3), 142-152.

Nonaka, I. (1990). Redundant, overlapping organization: A Japanese approach to managing the innovation process. California Management Review, 32(3), 27-38.

Nonaka, I., \& Konno, N. (1998). The concept of "Ba": Building a foundation for knowledge creation. California Management Review, 40(3), 40-54. 
Noorazah, M. N., \& Juhana, S. (2011). Factors influencing employee knowledge sharing capabilities in electronic government agencies in Malaysia. International Journal of Computer Science Issues, 8(4), 1694-0814.

Pai, J. C. (2006). An empirical study of the relationship between knowledge sharing and IS/IT strategic planning (ISSP). Management Decision, 44(1), 105-122.

Pavlou, P. A., \& Fygenson, M. (2006). Understanding and predicting electronic commerce adoption: An extension of the theory of planned behavior. MIS Quarterly, 115-143.

Pee, L.G, \& Lee, J. (2015). Intrinsically motivating employees' online knowledge sharing: Understanding the effects of job design. International Journal of Information Management, 35(6), 647-724.

Pérez, V. M., Cruz, N. M., \& Vaquero, I. E. (2012). The influence of organizational design on knowledge transfer. Journal of Knowledge Management, 16(3), 418-434.

Polit, D. F., \& Beck, C. T. (2011). Nursing Research: Generating and assessing evidence for nursing practice. $\left(10^{\text {th }}\right.$ ed.). China: Wolters Kluwer Health/Lippincott Williams \& Wilkins.

Ramachandran, S. D., Chong, S. C., \& Ismail, H. (2009). The practice of KM processes: A comparative study of public and private higher education institutions in Malaysia. The Journal of Information and Knowledge Management Systems, 39(3), 203-222.

Rempel, J. K., Holmes, J. G., \& Zanna, M. P. (1985). Trust in close relationships. Journal of Personality and Social Psychology, 49, 95-112

Reinholt, M., Pedersen, T., \& Foss, N. (2011). Why a central network position isn't enough: The role of motivation and ability for knowledge sharing in employee networks. Academy Management Journal, 54, 1277-1297.

Ryan, R. M., \& Deci, E. L. (2000). Intrinsic and extrinsic motivations: Classic definitions and new directions. Contemporary Educational Psychology, 25(1): 54-67.

Sharratt, M., \& Usoro, A. (2003). Understanding knowledge-sharing in online communities of practice. Electronic Journal on Knowledge Management, 1(2), 187-196.

Sohail, M. S., \& Daud, S. (2009). Knowledge sharing in higher education institutions: Perspective from Malaysia. Journal of Information and Knowledge Management System, 39(2), 125 142.

Sondergaard, S., Kerr, M., \& Clegg, C. (2007). Sharing knowledge: Contextualizing sociotechnical thinking and practice. The Learning Organization, 14(5), 423-435.

Spender, J. C., \& Grant, R. M. (1996). Knowledge and the firm: Overview. Strategic Management Journal, 17(S2), 5-9.

Susantri, A. I., \& Wood, P. C. (2011). The motivation to share knowledge of employee in the telecommunication service providers in Indonesia. Paper presented at the International Conference on Social Science and Humanity, IPEDR, 5, 159-162. Retrieved form http://www.ipedr.com/vol5/no2/36-H10117.pdf.

Susanty, A. I., Salwa, M., Chandradini, A., Evanisa, F. W., \& Iriani, N. (2016). Knowledge sharing and implementation of its enabling factors (A case study of three types of company in Indonesia). Pertanika Journal of Social Sciences \& Humanities, 24(S), 239-254.

Van den Hooff, B., Schouten, A. P., \& Simonovski, S. (2012). What one feels and what one knows: The influence of emotions on attitudes and intentions towards knowledge sharing. Journal of Knowledge Management, 6(1), 148-158.

Wang, H. K., Tseng, J. F., \& Yen, Y. F. (2012). Examining the mechanisms linking guanxi, norms and knowledge sharing: the mediating roles of trust in Taiwan's high-tech firms. The International Journal of Human Resource Management, 23(19), 4048-4068. 
Wang, H. K., Yen, Y. F., \& Tseng, J. F. (2015). Knowledge sharing in knowledge workers: The roles of social exchange theory and the theory of planned behavior. Innovation: Management, Policy \& Practice, 17(4), 450-465.

Wasko, M. M., \& Faraj, S. (2000). It is what one does: Why people participate and help others in electronic communities of practice. The Journal of Strategic Information Systems, 9(2-3), 155-173.

Wasko, M. M., \& Faraj, S. (2005). Why should I share? Examining social capital and knowledge contribution in electronic networks of practices. Management Information System, 29(1), 35-57.

Watkins, D. C. (2012). Qualitative research: The importance of conducting research that doesn't 'count'. Health Promotion Practice, 13(2), 153-158.

Watkins, D. C., \& Gioia, D. (2015). Mixed Methods Research (Pocket Guides to Social Work Research Methods Series). New York, NY: Oxford University Press.

Welschen, J., Todorava, N., \& Mills, A. (2012). An investigation of the impact of intrinsic motivation on organizational knowledge sharing. International Journal of Knowledge Management, 8(2), 23-42.

Willem, A. (2003). The role of organization specific integration mechanism in inter-unit knowledge sharing (Doctoral Dissertation, Ghent University, Belgium). Retrieved from https://biblio.ugent.be/publication/468308/file/5968175.

Yan, Y., \& Davison, R. M. (2013). Exploring behavioral transfer from knowledge seeking to knowledge contributing: The mediating role of intrinsic motivation. Journal of the American Society for Information Science and Technology, 64(6), 1144-1157.

Yang, J. T. (2008). Individual attitudes and organisational knowledge sharing. Tourism Management, 29(2), 345-353.

Zuckerman, M., Porac, J., Lathin, D., \& Deci, E. L. (1978). On the importance of selfdetermination for intrinsically-motivated behavior. Personality and Social Psychology Bulletin, 4(3), 443-446.

Notes:

i. The term Hadith is used to report the saying or an act or tacit approval or criticism by Islamic prophet Muhammad (peace be upon him). 